\title{
التلوث البيئي في المنطقة العربية: سمات ومقترحات
}

Environmental pollution in the Arab World: problems and solutions

خالا مصطفى Khaled Moustafa Editor of Arabic Science Archive (https://arabixiv.org) محرر الأرشيف العربي العلمي البريد الإلكتروني: Email: khaled.moustafa@arabixiv.org الإريبي

ملخص

تتميز المنطقة العربية عامة وشبه الجزيرة العربية خاصة بمناخ جاف وقائظ، ولكن لم يكن ذلك القيظ تاريخياً بالمستوى الذي نراه اليوم، الذي يستدعي تثنيل مكيفات تبريد حتى في شهور الثتاء (كانون أول وكانون ثاني وثباط حسب التقويم الثمسي). وتختلط حالياً الفصول الأربعة، وتتثابه الشهور في كثير من الأمصار العربية، فلا الثتاء شتاءً ولا الربيع ربيعاً كما كانا، وإنما تكاد تتحول جميعاً إلى فصل واحد طويل، متفاوت فقط من حيث شدة الحرارة ومدتها. ولأساليب الحياة الحديثة، في استغلال واستخدام وسائل الطاقة والإسراف والهلر على مختلف المستويات، تأثير سلبي في بيئة قاسية بالأساس، وتحتاج إلى إدارة ناجحة لمواردها وسبل الحفاظ عليها. وتفادياً لمخاطر بيئية أكبر، ينبغي على صناع القرار في المجال البيئي والعمراني اتخاذ تدابير وقائية وعلاجية سريعة وناجعة قبل فوات الأوان، وإلا فلا مناص من كارثة بيئية حقيقية على مستوى واسع، لا تتفع عندها الحلول الآنية مهما كانت ناجعة وفعالة. سيتم هنا مناقشة بعض مظاهر التلوث البيئي في البلاد العربية، وتقديم بعض المقترحات للحد من مخاطره وتقليل الهـر والإسراف للحفاظ على بيئة نظيفة ومستـامة.

\section{Abstract}

Climate in the Arab region is known to be hot and dry particularly in the Arabic peninsula. The magnitude of temperature degrees nowadays are relatively high compared with the past. People experience the need for artificial air condition permanently including in winter. The frontiers between seasons are subtle, making the four seasons as one long and hot season that the temperature intensities vary only slightly over the months. The reasons behind such weather shifts between the past and present are multiple, such as the full dependency on polluting fossil energy in all the economic sectors and heavy consumption society styles with the absence of environmental sustainability culture. Some aspects of environmental pollutions in the Arab world are discussed here along with suggestions to reduce them.

Keywords: air condition, Arab world, environmental conservation, environmental pollution, environmental sustainability, energy, fossil energy, oil dependency, sustainability. 
تقترن أسماء بعض الثهور العربية القمرية بكثير من الأمثال الثعبية، والصفات العامة المرتبطة بالمناخ المحيط للالالة على خصائص تللك الثهور عند تسميتها، كبرودة الطقس واعثداله أو سخونته. فمثلاً تشير أسماء جمادى الأولى وجمادى الثانية إلى أن الماء كان يتجمد خلا هذين الثهرين، وربيع الأول وربيع الثاني إلى جو ربيعي تتلطف فيه الحرارة والطقس عند تسمية تلك الثهور في الماضي البعيد. أما اليوم، فتكاد تتعدم تلك الفروقات مع استثناءات قليلة، حيث تكاد تمضى أشهر السنة، ولا يختلف الثهر عن الآخر إلا طفيفاً، خاصة في شبه الجزبرة العربية حيث يمكن وصف الثهور العربية بـ "لهيب الأول، لهيب الثاني، لهيب الثالث،... لهيب الثاني عثر" لتشابهها بالحرارة اللاهبة على مدار العام. ومن أبرز مظاهر الإحساس بالطقس الحار، وعواقبه على الحياة اليومية، هو انتشار التبربد الصناعي بمكيفات الهواء، الذي وإن كان يُخفف من تأثير الحرارة آنياً في حيز ضيق، لكنه يُفاقم المشكلة في حيز أكبر على إِى المدى المتوسط والبعيد، وبدخلها في دوّامة مفرغة، لأن التبربد وإن كان بعطي هواءً بارداً من جهة، فهو ينفث هواء ساخناً من الجهة الأخرى، ويسخن الهواء المحيط بأجهزة التبريد مما يجعل دورة التبريد والتسخين حلقة مفرغة مستمرة. ويمكن التأكد من هذه الحقيقة البسيطة بوضع البد خلف جهاز المكيف أو خلف البرّاد في حالة التشغيل المتواصل، واستشعار الحرارة الناجمة عنهما باليد، ثم إسقاط الأمر على كل أجهزة التبربد والتكييف المستخدمة في آن واحد على نطاق واسع (مدينة كبيرة مثناً)، سيتضح أن نشغيل المكيفات يتسبب في تسخين الهواء المحيط في دورة مستصرة من التبريد/تسخين/تبربد/تسخين... إلخ. وهذا ما قد لا يدركه المستهلك أو المواطن العادي، الذي همه فقط أن بشعر براحة آنية، والهروب من الحرارة اللاهبة، دون أن بعلم أن التبريد بشكل عام هو استهلاك مستمر لكميات كبيرة من الطاقة من جهة، وتخريب للبيئة من جهة أخرى، بتسخين الهواء وما بنجم عن ذلك من حرارة تتعكس سلباً على البيئة ومكوناتها الحيوبة وغير الحيوية. وبقدر ما يكون عدد المكيفات أكبر ، وفترة تشغيلها أطول، يزداد تسخين الهواء، وتزداد الحاجة إلى التبربد باستمرار. بمعنى آخر ، مككيفات التبريد هي حلّ لحظيّ فقط، يُفاقم المشكلة البيئية على المدى المتوسط والبعيد، لذا يجب البحث عن حلول أكثر نجاعة وديمومة وكفاءة، وأقل تلوبثاً للبيئة، وأقل حاجة إلى التكييف الصناعي، الذي يضر من حيث يُراد له أن ينفع. وليس الغرض من ذلك الدعوة إلى عدم استخدام التبربد الصناعي نهائياً، ولكن إلى التفكير والترشيد وإيجاد حلول ناجعة لجذور المشكلة، ولمظاهر الإسراف واللامبالاة في استخدام وسائل الحياة اليومية دون أي اعتبار للبيئة والأخطار لمحدقة بها، ولأن الحلول الآنية المُسكنة، وقصيرة المدى، لن تجدي نفعاً على المدى البعيد من وجهة نظر بيئية بحتة. 
ويمكن للارس أن يلاحظ بسهولة أن الوعي البيئي في الدول العربية يكاد يكون معدوماً نقريباً، علماً أن

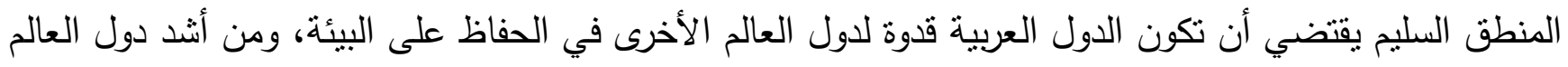

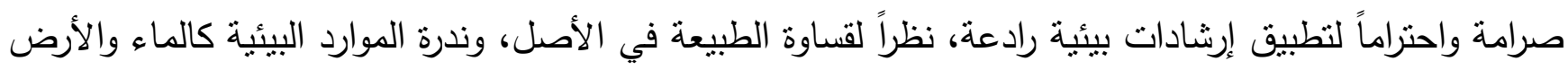

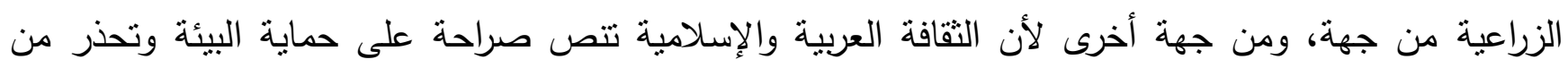

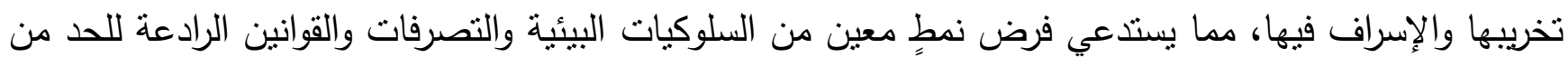
الآثار السلبية الضارة بما ينالاهم مع البيئة المحلية.

وتبدو الرغبة العارمة في الاستهلاك الباذخ والرفاهية الفرطة والأبهة، دون التفكير بالعواقب والسلبيات،

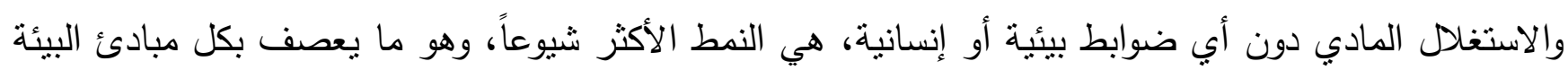

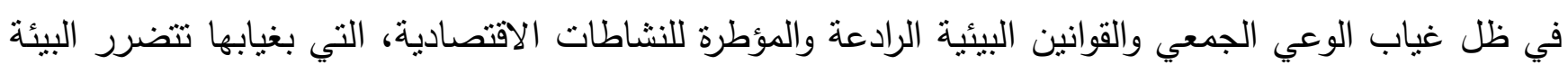
ويتفاقم التلوث وتتضخم أضراره باطراد.

\section{بعض سمات التلوث البيئي في البلاد العربية}

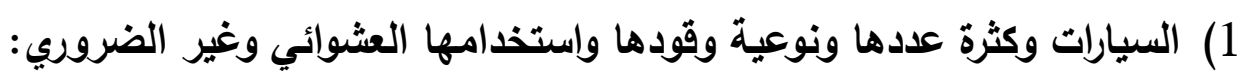

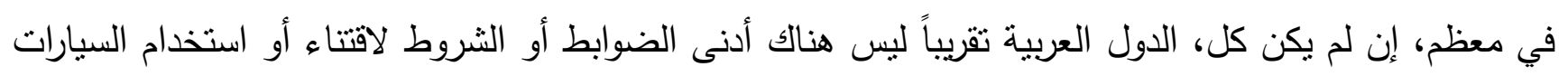

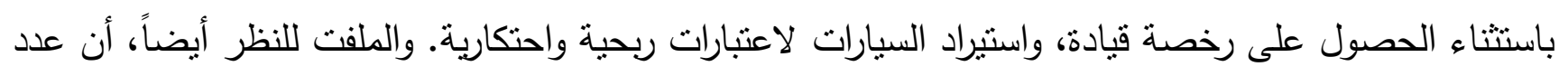

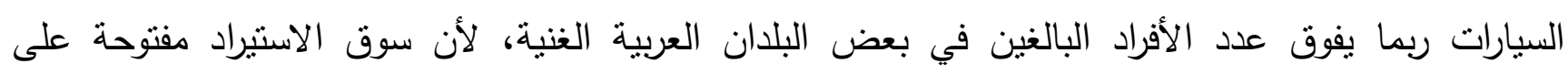

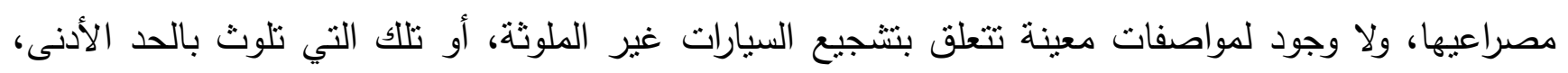

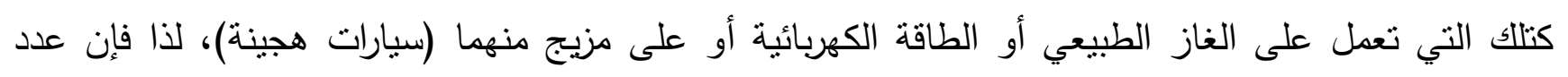

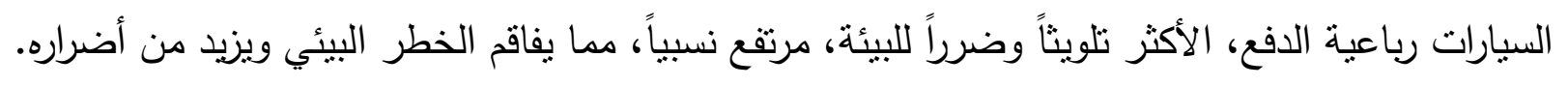

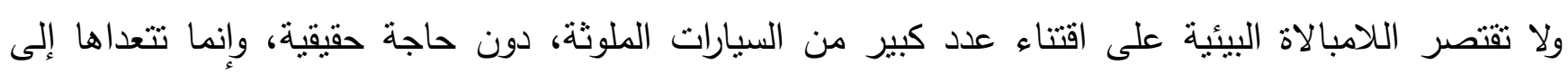

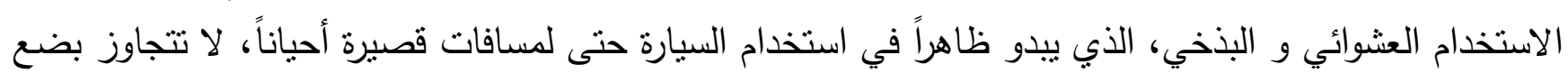

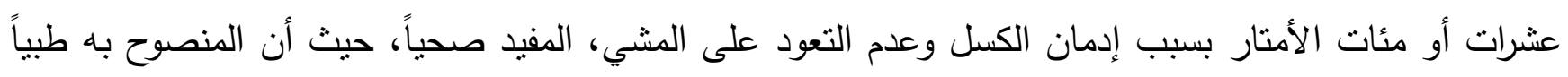

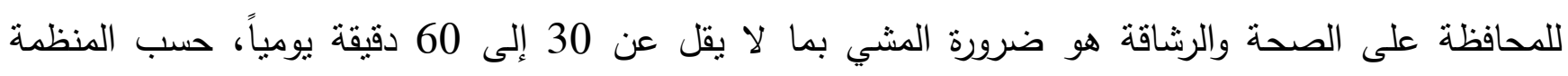
العالمية للصحة (http://www.who.int)

وتتكرس مظاهر الكسل هذه حتى لاى الثباب، على الرغم من كل ما تسببه من مشاكل صحية ومرضية، كالسمنة

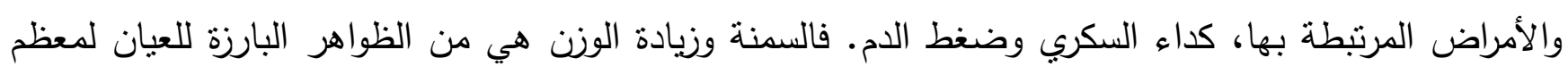

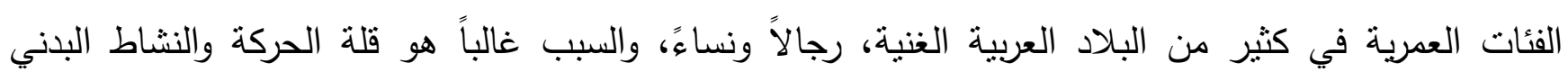

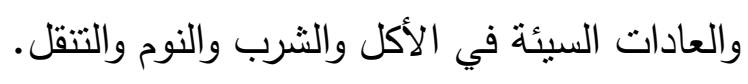


2) تثغيل المكيفات عادة أكثر منه حاجة: يبدو أن تشغيل المكيفات في بعض البلدان الخليجية قد أصبح عادة

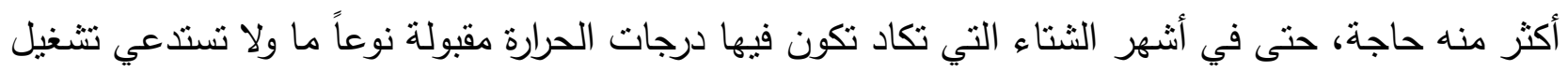

$$
\text { مكيفات التبريد. }
$$

3) العمل في الأنشطة الصناعية ليلاً ونهاراً، أو إلى ساعات متأخرة من الليل، وما يترتب على ذلك من استهلاك

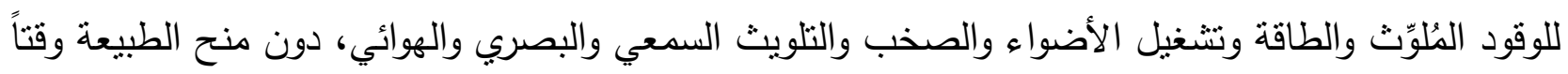

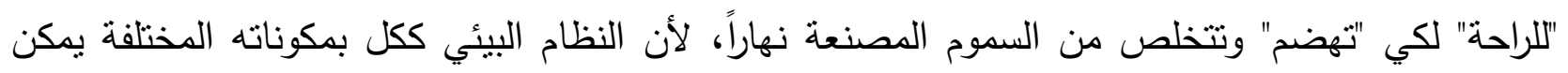
اعتباره ككائن حي معقد يحتاج إلى فترات راحة كي يهضم ويتخلص من السموم المنتجة خلال فترات التصنيع

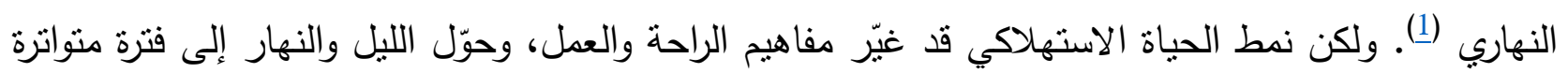
من العمل والاستهلاك والتلويث، مما ينعكس سلباً على مهام الحفاظ على بيئة سليمة ونظيفة. 4) معظم إن لم يكن كل الأجهزة الكهريائية في الدول النفطية تكاد تعمل على الطاقة الأحفورية (نفط وغاز ) على الرغم من وجود أفضل وأنظف مصدر للطاقة (الثمس) على مدار العام في معظم الدول العربية، حيث يمكن للاول العربية المشمسة أن تشجع، بل وتشترط على، مصنعي الأجهزة والتقنيات الحديثة تصنيع أجهزة

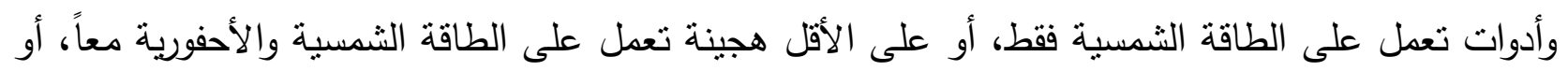

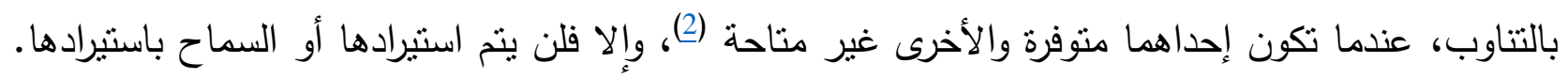
وهذا قابل للنطبيق، لأن التقنيات اليوم هي أكثر نطوراً من ذب قبل، وقادرة عادئ على جعل معظم الأجهزة التقنية والكهربائية، بما فيها الهواتف المحمولة والحواسب والسيارات وإنشارات المرور إلخ، تعمل على الثى الطاقة الثمسية وبكفاءة عالية. لذا، فإن انتراط الطاقة الثمسية كمدر للتغذية الكهبائية أمر أكثر من بديهي في الدول

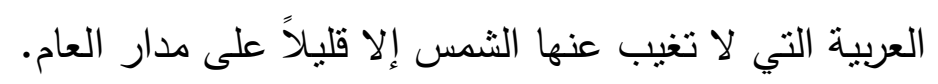
5) نوعية الأكل والثرب: كثير من الناس لا يكتفي بما يسد الرمق، ويقيم الصلب ويقوي العزم، وإنما يذهب إلى التى

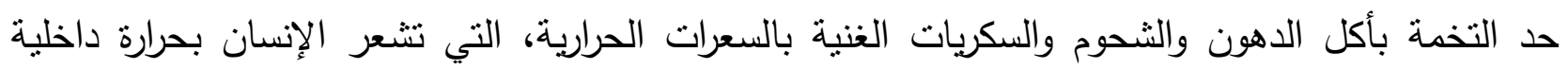

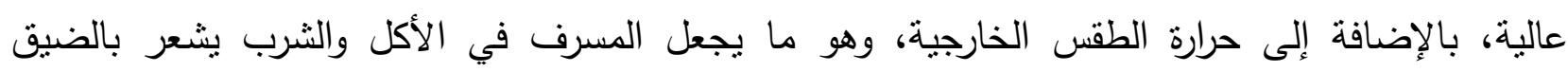

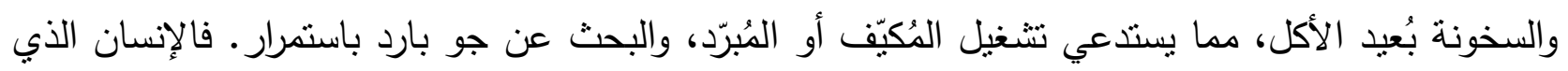

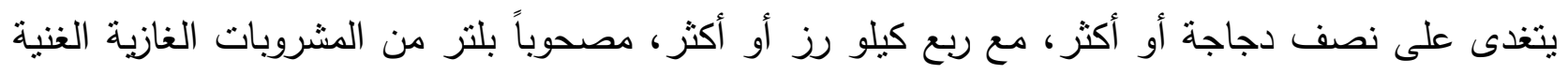

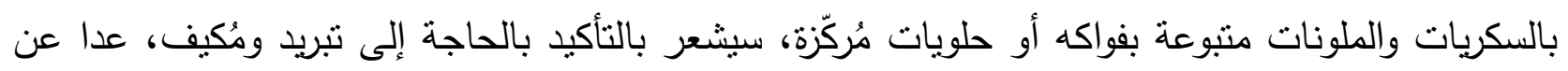

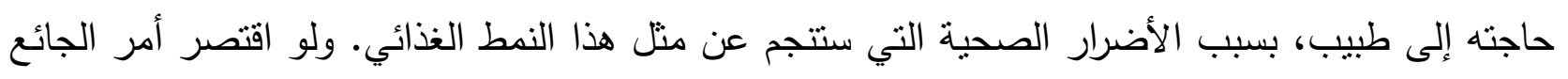

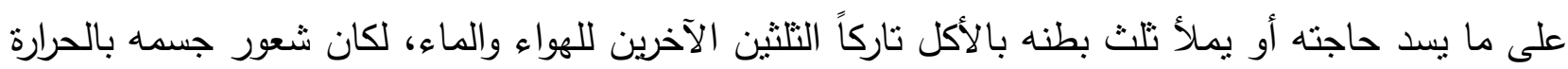
أخف، وصحته أفضل، وحاجته إلى تشغيل المكيفات أقل، وإضراره للبيئة ضئيلاً. 
وفي هذا السياق، تحتاج الجهات المعنية في الدول العربية، التي تتجلى فيها هذه المظاهر ، إلى سن قوانين واضحة تحد من الهدر والسرف في الطعام والثراب على المستوى العام من خلال بعض الإرشادات، مثل:

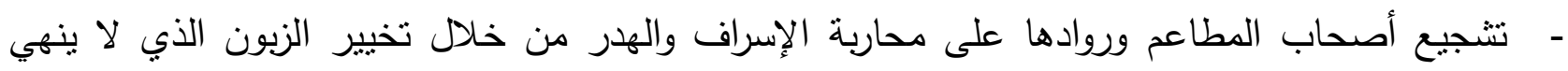

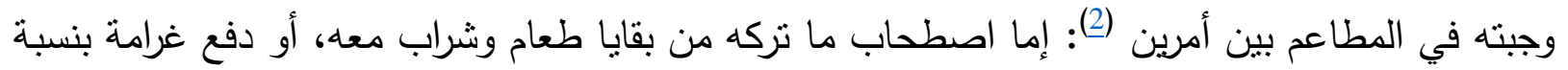

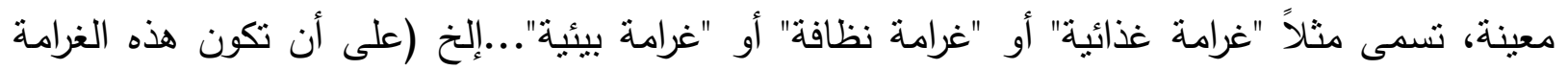

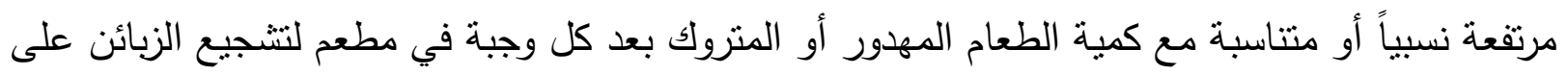

$$
\text { عدم الإنراف. }
$$

سيحقق منل هذا الإجراء فوائد جمة لصاحب المطعم أولاً، وللزبون ثانياً وللبيئة ثالثاً، منها: - - تقليل حجم النفايات الغذائية في المطاعم، وتوفير كميات كبيرة من الطعام المهدور . - زيادة مستوى النظافة حيث ستقل الحاجة إلى تتظيف بقايا الطعام المهدور من قبل الزبائن. - تقليل الهرر الغذائي والمالي الكُنفق على التخلص من النفايات، وشراء مواد وأدوات التنظيف وأجور عمال نظافة وخدمة إلخ. - - توفير ولو جزء يسير من مصاريف الغذاء لمن يصطحب ما تبقى من غذائه ليأكله لاحقاً في بيته، أو

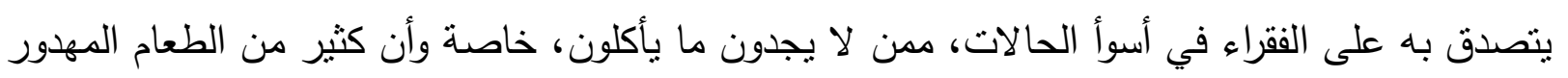

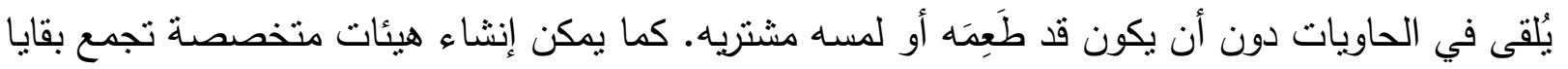
الطعام، وتقرز ما هو صالح للاستهلاك البشري، للتصدق به على المحتاجين، وما تبقى كعلف للأنعام.

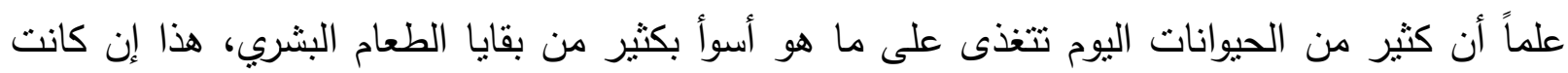
بقايا الطعام البشري سيئة أصلاً. وبذلك سيتم توفير كميات كبيرة من تكاليف انتاج وشراء الأعلاف الحيوانية.

أما من قد يعتبر أن أخذ بقايا الطعام أمر "مخجل" وفيه تعدٍ على الأنا والمكانة الاجتماعية، فهذه حجة "أقبح

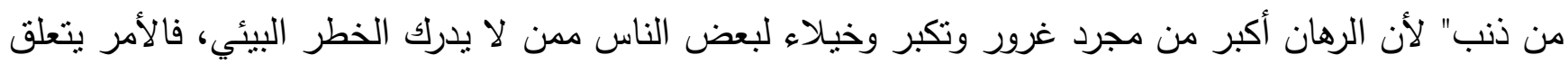
بمستقبله ومستقبل أبنائه وأحفاده وموارد بلده واقتصاده. والمثير للاستغراب والاستهجان في هذا الثأن، هو اعتقاد بعض الناس أن عدم إنهاء الطعام هو من "الوجاهة الاجتماعية وعلو الثأن والمقام"، فيلجؤون إلى عدم إنهاء

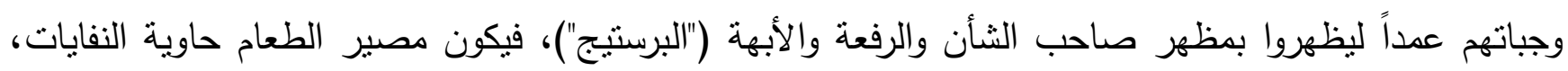

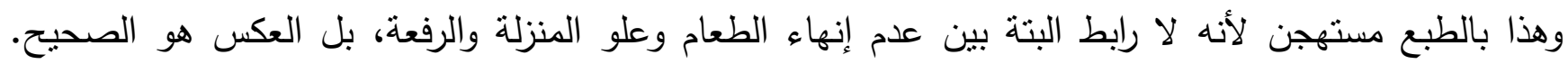
فالإسراف والهدر هما من علامات اللامبالاة والاستهتار بالنعمة والبيئة. 
اقتراحات للتقليل من مظاهر التلوث البيئي ونتائجه

- استخدام الأدوات والأجهزة والمعدات التقنية التي تعمل على الطاقة الثمسية حصراً (من خلاد السماح باستيراد المنتجات التي تعمل على الطاقة الثمسية فقط، أو هجينة، ومنع أو التقليل من استخدام أو استيراد

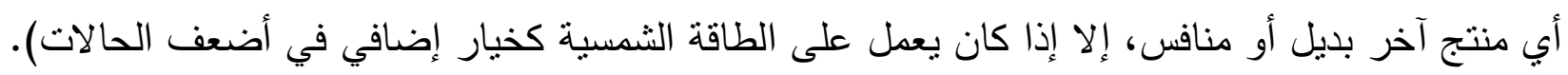

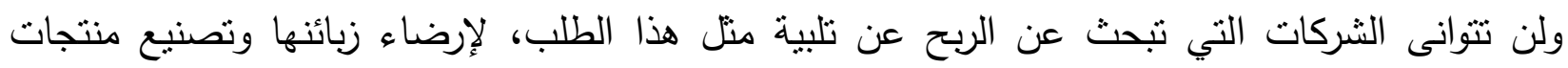

\section{حسب مواصفات معينة.}

- تشجيع استخدام الغاز الطييعي كوقود بديل عن الديزل والبنزين، إن لم تكن السيارات الكهربائية هي المعتمدة.

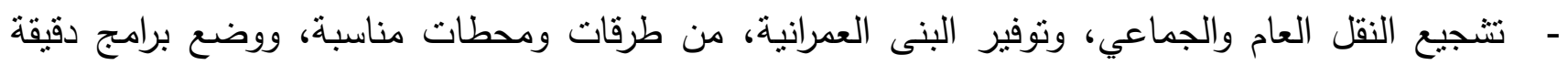
للتنفيذ، لأن حافلة واحدة تغني عن استخدام عشرات السيارات الخاصة، وتوفر ما تستهلكه من كميات كبيرة من وقود وما تتفثه من غازات سامة وملوثة في الجو . - تشجيع استخدام الدراجة الهوائية، على الأقل في الأثهر التي تكون فئه فيه فيه الحرارة مقبولة نسبياً. ففي أوروبا،

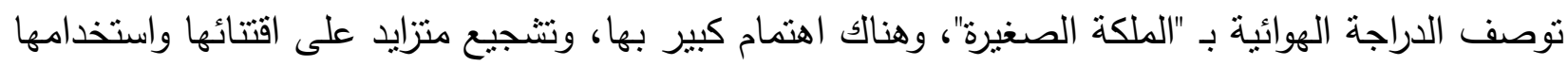

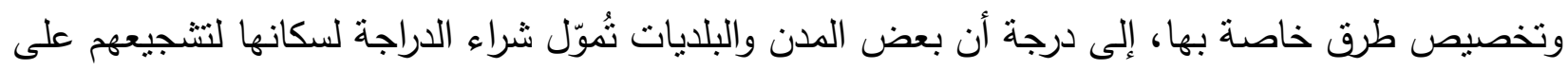

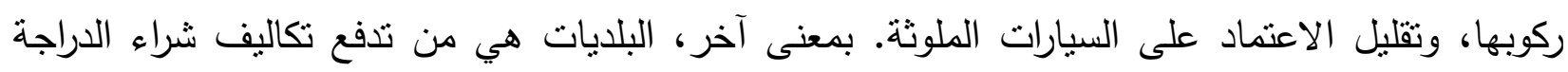

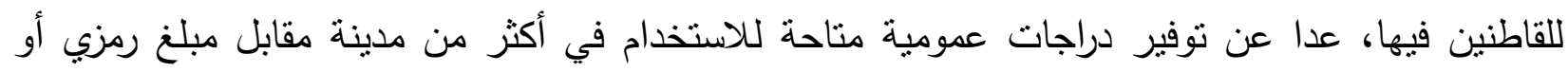
اشتراك سنوي بسيط نسبياً. بالمقابل، في بعض الدول العربية لا يزال يعتبر استخدام الدراجة عيباً أو انتقاصاً

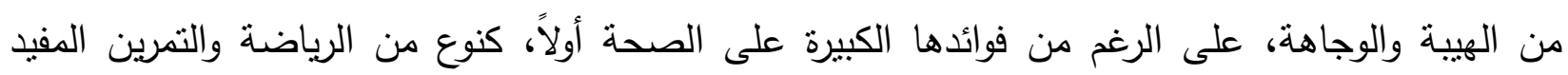
صحياً، وعلى البيئة ثانياً لخفض نسبة التلوث عندما تستخدم كبديل عن السيارة الملوثة.

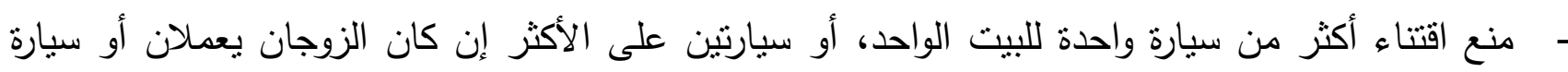

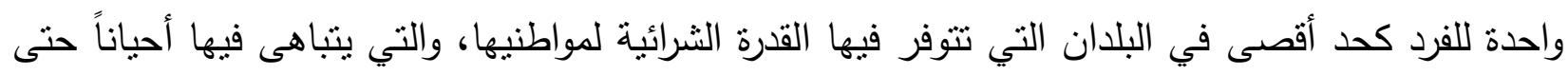

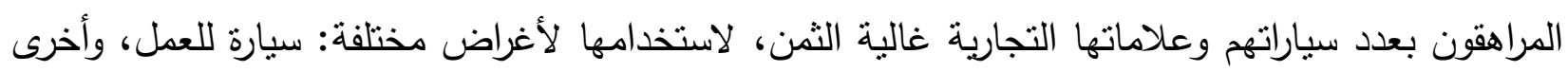

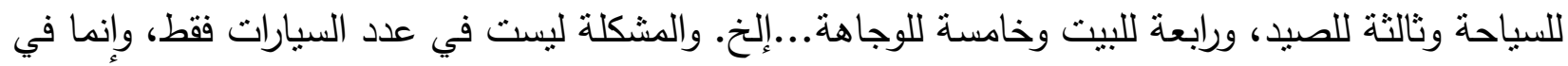

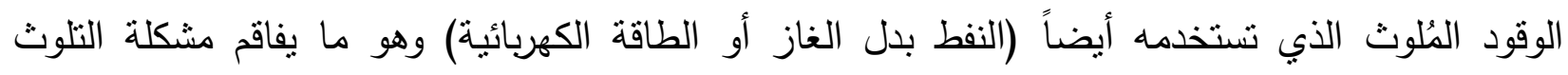

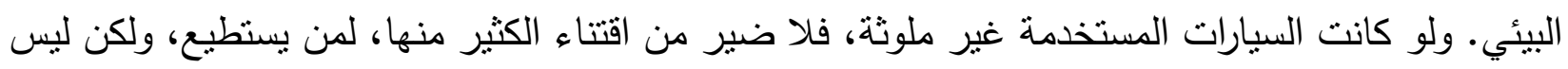
الأمر كذلك.

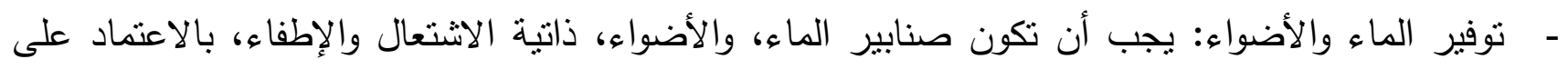

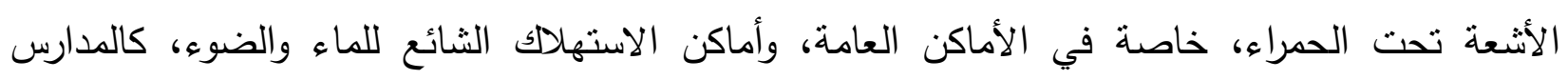


والجامعات والدوائر الحكومية والمطاعم...إلخ، وهذا لا يوفر كميات كبيرة من الماء والطاقة فحسب، بل ويساهم أيضاً في تقليل التلوث والعدوى الناجمين عن اللمس المتكرر للحنفيات والأزرار عند مرور المستخدمين بعضهم وراء بعض واستخدامهم لتلك التجهيزات. - إجراء حملات توعية بيئية مستمرة في كل وسائل الإعلام، المرئية والمسموعة والمقروءة، وفي المدارس

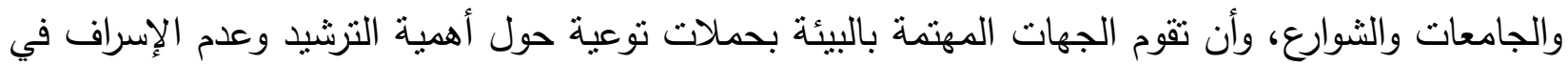
الماء والغذاء، والقيام بقياس مستويات التلوث الهوائي بانتظام، بغية استتباط حلول مناسبة وإجراءات فعالة يمكن اتخاذها في الوقت المناسب لكل حالة. - - مإجراء دراسات جادة كأطروحات دكتوراه أو ما بعد الدكتوراه لسبر نتائج وتغيّرات السلوك البيئي، والحصول على نتائج معنوية وذات دلالة بيئية على المستوى البعيد، منها على سبيل المثال لا الحصر :

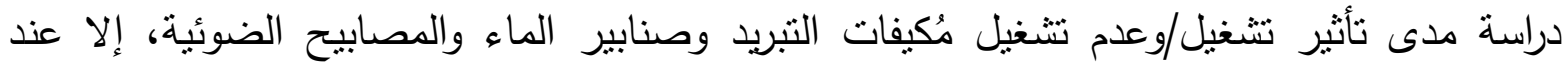
الضرورة، وحساب كميات الماء والطاقة الحرارية المنبعثة من كل صنبور /مصباح ضوئي، وكمية الطاقة التي يمكن توفيرها في حال الترشيد وعدم الاستخدام العشوائي لتلك الأجهزة. فلو تم أخذ عدد معين من

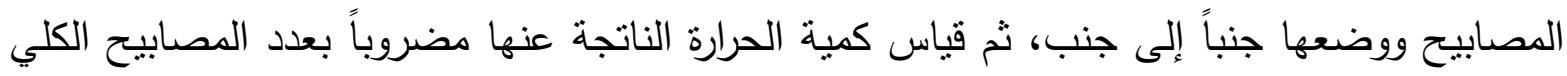
(وسطياً) لمدينة ما أو بلد ما، فيمكن أخذ فكرة عامة عن حجم الهواء الذي تسخنه تلألك المصابيح، وكمية الطاقة المستهلكة فعلياً والمهدورة سرفاً، وتلك التي يمكن توفيرها خلال سنة/أو سنوات/أو عشرات

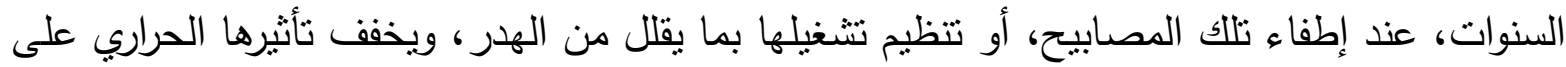
الوسط المحلي المحيط. وينطبق نفس الأمر على صنابير الماء لحساب كميات المياه التي يمكن توفيرها

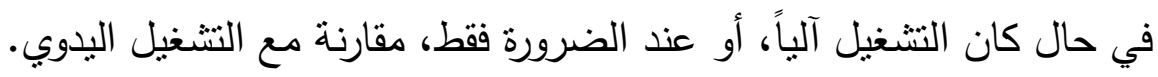
دراسة تأثثر السيارات وعوادمها على الطقس المحلي بحساب كمية الانبعاثات الغازية شهرياً، وسنوياً وعقدياً (خلال عشر سنوات) إلخ، بمعرفة متوسط عدد السبارات في مدينة ما، وكمية الانبعاث الغازي من كل سيارة، ثم حساب نسبة الملوثات التي يمكن تخفيضها في حال تم الاستغناء عن استخدام عدد

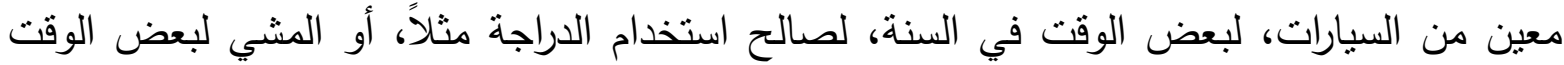
بدلاً من ركوب السيارة. دراسة حول كمية الطعام والنفقات التي يمكن توفيرها بتقليل الهرر والإسراف الغذائي في المطاعم والبيوت، ومقارنتها مع الوضع الحالي الذي ثُرمى فيه كميات كبيرة من الأطعمة، التي قد تكفي لإطعام

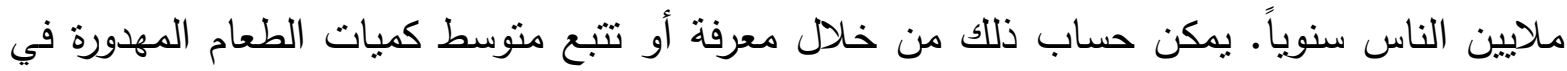
المطاعم والبيوت خلال فترة معينة من الزمن، أسابيع أو بضعة أثنهر ، ثم إسقاطها على فترات أطول. 
هراسة مقارنة استخدام النقل الجماعي مع النقل الخاص، وانعكاس ذلك على التكاليف العامة، ونسبة الغازات الملوثة في الجو، ومدى تأثثر ذلك على مستوى درجات الحرارة المحلية، في محيط صغير إلى لى منتوسط، ثم عام أو واسع.

وأخيراً، لا بد من الإشارة إلى إن الحفاظ على البيئة ليس منتجاً فاخراً يمكن استيراده أو تصديره مغلفاً بأبهى صورة

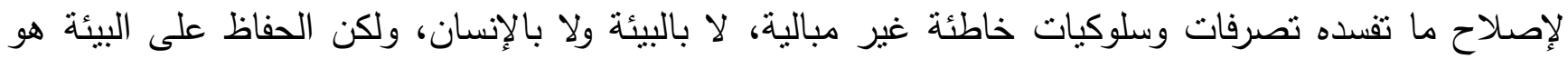

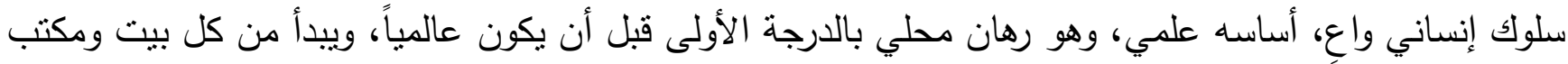
وموقع عمل، لينتهي إلى كل قرية ومدينة وبلد. ويحتاج الحفاظ على البيئة إلى جهود حثيثة، ورغبة قوية، وحملات

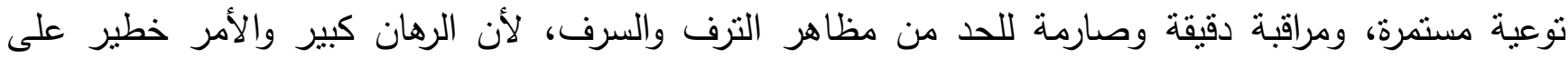
مستقبل الإنسان وبيئته معاً. إن سياسة الاستهلاك المفرط وتجاهل العواقب هي أصل كثير من المشاكل البيئية (3) لأنها تقتضي زيادة الانتاج

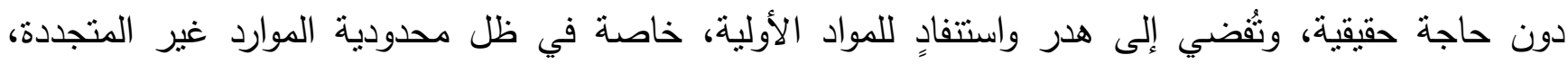
وغياب نقافة احترام البيئة، وصناعة التدوير ومعالجة مخلفات القمامة الناتجة عن الأبنية السكنية والأنشطة الصناعية والكيمبائية والزراعية.

تستدعي تلك المظاهر ومظاهر أخرى كثيرة وقفة جادة وحازمة من قبل المتمين بالثمؤون البيئية لاتخاذ خطوات تطبيقية عاجلة، وسن قوانين رادعة للحفاظ على بيئية مستدامة ونظيفة، وتقليل الهدر والإسراف واللادبالاة البيئية، لأنها إذا استمرت دون علاج، أو وقاية، فإن آثارها ستتعكس سلباً وضرراً على الجميع، دون استثناءٍ لمنصب أو وأوله

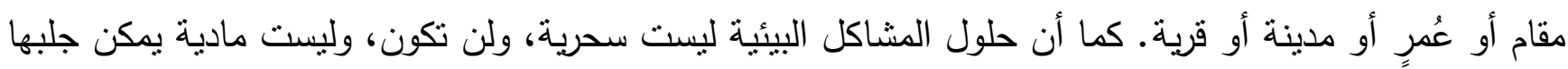
من وراء البحار، وإنما تكمن في تطبيق إرشادات صارمة، اليوم قبل الغد، وتغيير جذري في منهج الحياة والسلوك البذخي والإسرافي، وزيادة الوعي الجمعي بخطورة الوضع البيئي، وضرورة الإسراع باتخاذ تدابير وقائية وعلاجية، وإلا فالكارثة البيئية الهذامة قادمة مع كل ما يرافق ذلك من تداعيات وانعكاسات خطيرة وضارة على كل مناحي الحياة الإنسانية، من تصحر وجفاف وقحط وجدب وفقر ومرض وتقلص مساحة الأرض الزراعية وندرة الماء

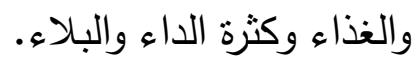

\section{References}

1. $\quad$ Moustafa, K., A clean environmental week: Let the nature breathe. Sci Total Environ, 2017. 598: p. 639646.

2. Moustafa, K., Food and Sustainability Challenges Under Climate Changes. Sci Eng Ethics, 2016. 22(6): p. 1831-1836. 
3. Moustafa ,K., Exploit and ignore the consequences: A mother of planetary issues. Sci Total Environ, 2016. 557-558: p. 912-3. 